\title{
European clinical guidelines for Tourette syndrome and other tic disorders-version 2.0. Part IIl: pharmacological treatment
}

\author{
Veit Roessner ${ }^{1} \cdot$ Heike Eichele ${ }^{2,3} \cdot$ Jeremy S. Stern ${ }^{4} \cdot$ Liselotte Skov $^{5} \cdot$ Renata Rizzo $^{6} \cdot$ Nanette Mol Debes $^{5}$. \\ Péter Nagy ${ }^{7}$. Andrea E. Cavanna ${ }^{8}$. Cristiano Termine ${ }^{9} \cdot$ Christos Ganos $^{10} \cdot$ Alexander Münchau ${ }^{11}$. \\ Natalia Szejko ${ }^{12,13,14}$. Danielle Cath ${ }^{15} \cdot$ Kirsten R. Müller-Vahl ${ }^{16}$. Cara Verdellen ${ }^{17,18}$. Andreas Hartmann ${ }^{19,20}$. \\ Aribert Rothenberger ${ }^{21} \cdot$ Pieter J. Hoekstra ${ }^{22} \cdot$ Kerstin J. Plessen ${ }^{23,24}$
}

Received: 28 March 2021 / Accepted: 24 October 2021 / Published online: 10 November 2021

(c) The Author(s) 2021

\begin{abstract}
In 2011, the European Society for the Study of Tourette Syndrome (ESSTS) published the first European guidelines for Tourette Syndrome (TS). We now present an update of the part on pharmacological treatment, based on a review of new literature with special attention to other evidence-based guidelines, meta-analyses, and randomized double-blinded studies. Moreover, our revision took into consideration results of a recent survey on treatment preferences conducted among ESSTS experts. The first preference should be given to psychoeducation and to behavioral approaches, as it strengthens the patients' self-regulatory control and thus his/her autonomy. Because behavioral approaches are not effective, available, or feasible in all patients, in a substantial number of patients pharmacological treatment is indicated, alone or in combination with behavioral therapy. The largest amount of evidence supports the use of dopamine blocking agents, preferably aripiprazole because of a more favorable profile of adverse events than first- and second-generation antipsychotics. Other agents that can be considered include tiapride, risperidone, and especially in case of co-existing attention deficit hyperactivity disorder (ADHD), clonidine and guanfacine. This view is supported by the results of our survey on medication preference among members of ESSTS, in which aripiprazole was indicated as the drug of first choice both in children and adults. In treatment resistant cases, treatment with agents with either a limited evidence base or risk of extrapyramidal adverse effects might be considered, including pimozide, haloperidol, topiramate, cannabis-based agents, and botulinum toxin injections. Overall, treatment of TS should be individualized, and decisions based on the patient's needs and preferences, presence of co-existing conditions, latest scientific findings as well as on the physician's preferences, experience, and local regulatory requirements.
\end{abstract}

Keywords Tics · Tourette syndrome $\cdot$ Pharmacotherapy $\cdot$ Medication $\cdot$ Treatment

\section{Introduction}

The first European clinical guidelines for Tourette Syndrome $\left(\mathrm{TS}^{1}\right.$ ) were published in 2011 [1] by working groups of the European Society for the Study of Tourette Syndrome (ESSTS) and provided recommendations for the assessment and treatment of TS based on existing guidelines, metaanalyses, reviews, clinical trials, and case studies up to that

This article is part of the focused issue "Update of the European clinical guidelines for Tourette Syndrome and other tic disorders".

Veit Roessner

veit.roessner@uniklinikum-dresden.de

Extended author information available on the last page of the article point. The present guideline provides clinicians an update of recommendations for the pharmacological treatment of TS in Europe using evidence from clinical trials and clinical expertise.

In general, clinical guidelines rely on the combination of information from controlled clinical trials (including their shortcomings) and clinical (consensus-based) knowledge, given the lack of sufficiently comprehensive and detailed evidence. Regarding TS, the situation mentioned in our 2011 article with "...only a limited number of studies on pharmacological treatment options for TS met rigorous quality

\footnotetext{
$\overline{1}$ We use the term TS in these guidelines, wherever information also applies to other forms of tic disorders. Only if there are substantial, well-known differences between TS and other forms of tic disorders we use TS or other terms, e.g. transient or chronic motor tic disorder.
} 
criteria..." still holds true. Especially head-to-head comparisons of different agents or their combination as well as optimal treatment duration and dosage have not been systematically investigated, hence calling for an approach supplemented by knowledge from clinical practice. Moreover, the effectiveness of pharmacological treatments in reducing tics varies between trials as a result of differences in methodology and patient characteristics. Furthermore, controlled studies in treatment resistant cases are lacking. It remains common practice to have to try various options until an effective reduction of tics is achieved [2].

Recently, a systematic review and guidelines of the American Academy of Neurology (AAN) for the treatment of TS have been published [3, 4]. The authors of the AAN guidelines used structured, evidence-based methodology as outlined in the 2011 edition of AAN's guideline development process manual. To formulate new European recommendations for the pharmacological treatment of TS, we complemented the English-language literature since 2011 and combined it with the results of a survey among ESSTS experts, who were asked about their pharmacological daily practice in children and adults with TS.

\section{Methodology of selection of agents and literature search strategy}

To select relevant agents, we combined agents with at least moderate or low evidence according to the guidelines of the AAN [3,4] with those mentioned in our European survey. For these agents, we reviewed the English-language literature since 2011 in PubMed using the agent's name in combination with "tics", "tic disorder", or "Tourette Syndrome", including children, adolescents, and adults as search string. In addition, we checked the references since 2011 of other systematic reviews/metaanalyses [5-9], existing guidelines [3, 4, 10-12], nonsystematic reviews on TS with statements about pharmacological treatment, i.e., dealing with various agents [13-38] or mentioning treatment in their title [39-64]. In addition, we had a look into the references of agentspecific reviews and meta-analyses of (in alphabetical order) aripiprazole [65-72], atypical antipsychotics [73], botulinum toxin [74-85], cannabis [86-88], clonidine $[89,90]$, complementary alternative medicine [91], deutetrabenazine [92], non-dopaminergic agents [93], traditional Chinese medicine [94], and topiramate [95, 96]. Moreover, we screened references of reviews on specific aspects of TS if they describe treatment options for coexisting attention deficit hyperactivity disorder (ADHD) [97-103], obsessive-compulsive disorder (OCD; [104, 105], autism and stereotypies [106, 107], adverse events of pharmacological treatment in TS [108, 109], and treatment resistant TS [110].

\section{Agents from recently published AAN guidelines}

The authors of the AAN guidelines included only systematic reviews and randomized controlled trials (RCTs) on the treatment of tics that included at least 20 participants. They concluded that there is "....moderate confidence that haloperidol, risperidone, aripiprazole, tiapride, clonidine, botulinum toxin injections, 5-ling granule, and Ningdong granule were probably more likely than placebo to reduce tics....". Lower confidence was reported for pimozide, ziprasidone, metoclopramide, guanfacine, topiramate, and tetrahydrocannabinol (THC). Strong confidence was demonstrated only for behavioral approaches for tics (for detailed description of the behavioral approaches consult Part II of our guidelines).

\section{Agents mentioned in the ESSTS survey}

In the survey of the ESSTS Guidelines Group conducted in 2019, ESSTS experts' prescription practices for the treatment of TS were gathered. They were asked which medication they would consider as first, second, third, and subsequent choices, provided absence of contra-indications for the available agents and absence of co-existing conditions. Contrary to our prior survey from 2011 [111], we also asked the experts to give their recommendations separately for children/adolescents and adults.

In general within the answers of 59 clinicians, choices in children/adolescents did not differ from those in adults and pointed to a high preference for aripiprazole in both age groups. The main difference between the age groups was that haloperidol was much more commonly considered in adults, while in children/adolescents tiapride was more often mentioned (for details consult, Table 1). When comparing the results of our ESSTS surveys performed in 2011 and in 2019, a clear shift over the last decade can be seen from risperidone, pimozide, and (ami)sulpiride in favor of aripiprazole (Fig. 1).

We also collected experts' opinion on the reason for starting pharmacological treatment of TS. Fifty-nine clinicians treating patients with TS who were members of ESSTS (95\% from Europe) regarded as most important reason that the "patient/parents requested medication", followed by "behavior therapy had not been successful", and finally "high severity of tics". While $81 \%$ of clinicians would use pharmacotherapy as first-line to treat severe tics, in the case of moderate tics this was done only by $34 \%$, and in the case of mild tics by $3 \%$ of clinicians (for detailed description of the survey's results consult Part V of this issue).

\section{Selection of agents to be discussed in detail}

From the moderate confidence group in the AAN guidelines [3] all agents except 5-ling granule and Ningdong 
Table 1 Preferences of agents for treatment of TS
Fig. 1 Results from ESSTS surveys on preferences of agents for the treatment of tics in 2011 compared to 2019. In 2011, responses from 22 TS experts were received, while in 201950 ESSTS experts (45 responses for treatment in adults and 50 in children/adolescents, findings shown together). Each first choice agent was rated with 4 points, a second-choice agent with 3 points, a thirdchoice agent with 2 points, and additional agents with 1 point. In 2011, 1 point was given for desipramine, thioridazine, oxcarbazepine (not shown in the figure)

\begin{tabular}{|c|c|c|c|c|c|}
\hline \multicolumn{3}{|c|}{$\begin{array}{l}\text { Children and adolescents ( } n=15 \text { different agents were } \\
\text { given) }\end{array}$} & \multicolumn{3}{|c|}{ Adults ( $n=14$ different agents were given) } \\
\hline \multirow{2}{*}{$\frac{\text { Points }}{141}$} & \multicolumn{2}{|l|}{ Percentage } & \multirow{2}{*}{$\begin{array}{l}\text { Points } \\
127\end{array}$} & \multicolumn{2}{|c|}{ Percentage } \\
\hline & 29.2 & Aripiprazole & & 31.0 & Aripiprazole \\
\hline 82 & 17.0 & Clonidine & 70 & 17.1 & Haloperidol \\
\hline 81 & 16.8 & Tiapride & 37 & 9.0 & Clonidine \\
\hline 49 & 10.1 & Guanfacine & 32 & 7.8 & Risperidone \\
\hline 25 & 5.2 & Atomoxetine & 26 & 6.3 & Quetiapine \\
\hline 20 & 4.1 & Risperidone & 20 & 4.9 & Botulinum toxin \\
\hline 18 & 3.7 & Topiramate & 17 & 4.1 & Cannabinoids \\
\hline 18 & 3.7 & Cannabinoids & 14 & 3.4 & Pimozide \\
\hline 15 & 3.1 & Pimozide & 11 & 2.7 & Guanfacine \\
\hline 11 & 2.3 & Amisulpiride & 11 & 2.7 & Amisulpiride \\
\hline 8 & 1.7 & Tetrabenazine & 10 & 2.4 & Topiramate \\
\hline 5 & 1.0 & Quetiapine & 10 & 2.4 & Atomoxetine \\
\hline 4 & 0.8 & Haloperidol & 9 & 2.2 & Tetrabenazine \\
\hline 3 & 0.6 & Botulinum toxin & 8 & 2.0 & Tiapride \\
\hline 2 & 0.4 & Sertraline & 8 & 2.0 & Sertraline \\
\hline 1 & 0.2 & Sulpiride & & & \\
\hline 483 & 100 & & 410 & 100 & \\
\hline
\end{tabular}

Choices are given separately for children/adolescents and adults. We received 50 responses for children/ adolescents and 45 responses for adults (from 50 ESSTS experts; overlap in many cases). We rated each first-choice agent with 4 points, a second-choice agent with 3 points, a third-choice agent with 2 points, and additional agents with 1 point. To enable a comparison of the preferences between both age groups we calculated percentages

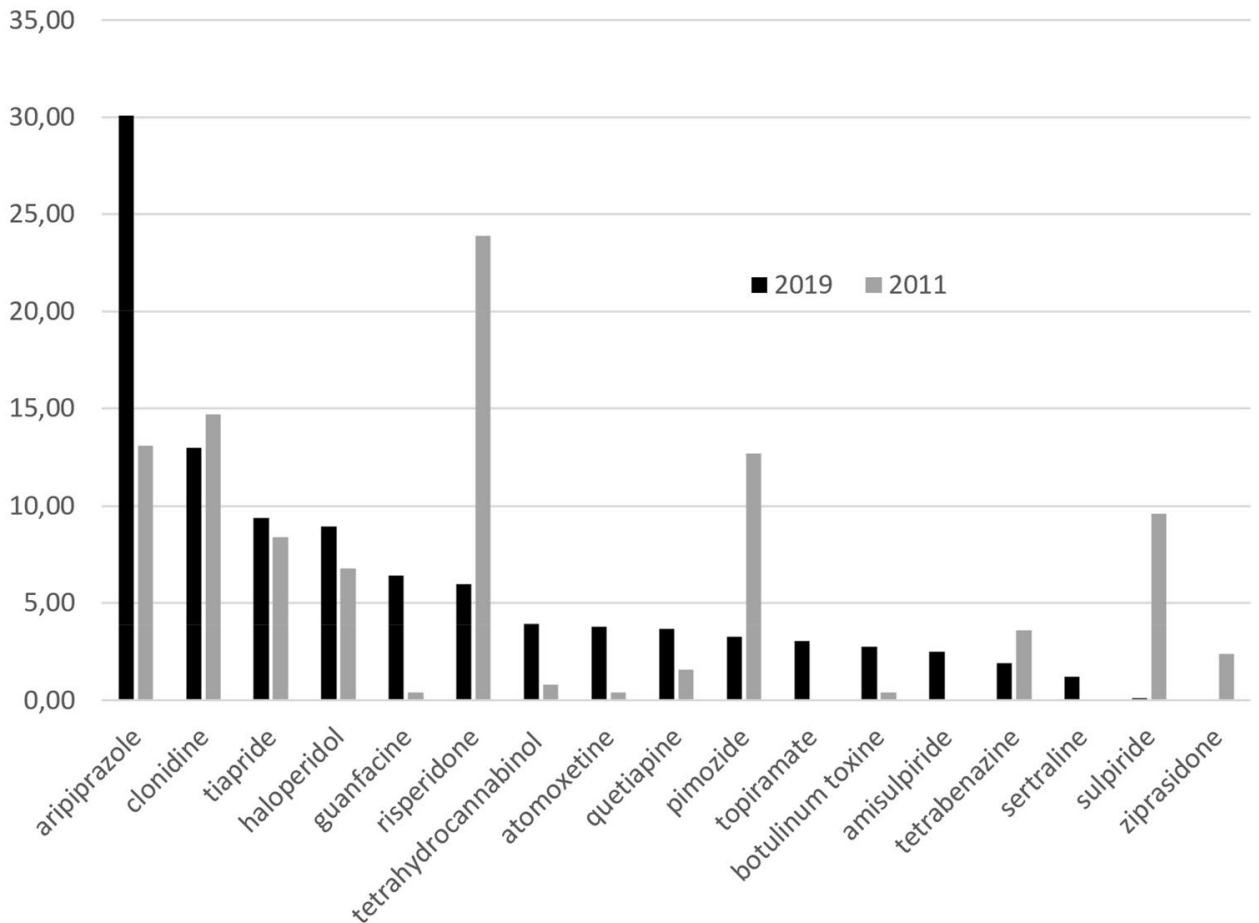

granule were commonly prescribed by ESSTS experts (see Table 1). From the lower confidence group only ziprasidone and metoclopramide were not prescribed by ESSTS experts.
Vice versa, amisulpiride, tetrabenazine, quetiapine, sertraline, atomoxetine, and sulpiride were mentioned by ESSTS experts as prescribed agents but not in the list of agents with 
at least moderate or low evidence according to the AAN guidelines.

\section{Dysfunction of transmitter systems as basis for psychopharmacological treatment}

TS has been associated with a dysfunction of many neurotransmitter systems, especially the dopaminergic system [39, 112]. Based on findings from nuclear imaging studies, four hypotheses on dopamine dysfunction in TS have been postulated: (1) dopamine hyper-innervation within the striatum; (2) supersensitive postsynaptic striatal dopamine receptors; (3) presynaptic dopamine abnormality in dopa carboxylase; and (4) elevated intrasynaptic dopamine release as a result of an imbalance between tonic and phasic dopamine levels [112]. Besides a dysfunction in the dopaminergic system, imbalances in other neurotransmitter systems have been suggested including serotonergic, noradrenergic, glutamatergic, GABAergic, cholinergic, histaminergic, endocannabinoid, and opioid systems [34, 39]. These findings give some rationale to use substances other than dopamine blocking drugs particularly for the treatment of tics resistant to dopamine-modulating agents.

\section{Dopamine-modulating agents}

The first agents used in treating tics were first-generation antipsychotics approved by the Food and Drug Administration (FDA), e.g. haloperidol (in 1969) and pimozide (in 1984), whereas aripiprazole was approved in 2014. In European countries, only haloperidol has been licensed for TS [113]. Discrepancies concerning the licensing of the same agents in Europe and the US largely stem from differences in interests of pharmaceutical companies between the US and Europe. In general, adverse effects of dopamine receptor antagonists are broad, ranging from extrapyramidal adverse effects including acute dystonia, parkinsonism, and akathisia to metabolic adverse effects including weight gain, type 2 diabetes mellitus, lipid spectra abnormalities, blood pressure changes, fatigue, headache, body temperature dysregulation, hyperprolactinemia, and sexual dysfunction, increase of prolactin levels, and QTc-prolongation as well as 'behavioral' changes, such as concentration problems, apathy, anhedonia and sedation, aggression, anxiety, and agitation [114, 115]. The limited existing evidence does not allow to predict individual potential adverse effects preceding the start of treatment [116]. Regarding hyperprolactinemia, antipsychotics with tight D2-binding predictably lead to hyperprolactinemia ("prolactin-raising"), whereas antipsychotics with loose D2-binding and partial agonistic action (e.g., aripiprazole) are considered as "prolactin-sparing" [117]. While most experts recommend measurement of prolactin levels before and during treatment with antipsychotics, long-term effects of hyperprolactinemia on sexual, bone, and breast development without accompanying acute clinical symptoms are unknown. Accordingly, the question of whether switching to another antipsychotic only because of hyperprolactinemia (without any clinical symptoms) is still a matter of debate [109, 118].

First-, second-, and third-generation antipsychotic agents are all being used in TS. First generation antipsychotics show predominantly extrapyramidal adverse effects and sedation, while second-generation drugs have more metabolic adverse effects (i.e., weight gain, disturbed blood lipid spectra, a higher risk of diabetes, and other metabolic adverse effects [108, 119, 120]). Second- and third-generation antipsychotics are more widely used and have a mode of action that is distinct from first generation antipsychotics' mode of action, by their binding to both dopamine and 5-HT2 receptors, i.e., their 5-HT2A receptor antagonism [51]. In line with this observation and despite the absence of regulatory approval for their use in TS for the majority of agents (with the exception of aripiprazole in the US), treatment recommendations favor the use of newer generation antipsychotics rather than first generation antipsychotics as first line treatment for tics, predominantly because of a more favorable tolerability with respect to extrapyramidal adverse effects $[111,115$, 121]. In the following paragraphs we review the various antipsychotics that may be used as treatment of TS.

\section{First-generation antipsychotics}

\section{Haloperidol}

Haloperidol was the first antipsychotic medication proven to be effective in the treatment of TS and is in the EU still the only agent with approval for TS. It is a potent dopamine antagonist, specifically against dopamine $\mathrm{D} 2$ receptors. It also blocks muscarinic acetylcholine receptors as well as adrenergic receptors and has a well-documented effectiveness in tic reduction $[6,111]$. Since 2011, no new English-language RCTs have been published in TS. The most recent meta-analysis (including also Chineselanguage RCTs) of haloperidol as treatment for TS pointed to a standardized mean difference compared with placebo of 3.20 (95\% CI [0.14-6.52]) [6].

However, due to considerable adverse effects (particularly parkinsonism, apathy, anhedonia, and QTc-prolongation), the use of haloperidol as treatment of TS has decreased within the last three decades from being a firstline agent to being used only in carefully selected, severely affected, and otherwise treatment resistant patients [3, 4, 10]. 


\section{Pimozide}

Pimozide is a dopamine D2 receptor antagonist which also blocks calcium channels. In the past, it has been one of the most frequently used medications in the treatment of tics [115] despite only a limited number of trials comparing its effectiveness to placebo or other agents [122]. Since 2011, no new English-language RCTs have been published in TS. Although several reviews give some support that pimozide is effective as treatment of tics, a recent metaanalysis (including also Chinese-language RCTs) did not find that pimozide is significantly better than placebo [6]. Moreover, due to its prominent adverse effects including drowsiness and risk of extrapyramidal symptoms (EPS), although to a lesser extent as compared to haloperidol [9, 122], weight gain (less than risperidone, but more than aripiprazole), sedation [9, 122-124], and the risk of QTc prolongation [9, 122], its application has declined noticeably [125]. Similar to haloperidol, in current guidelines it is recommended only in severely affected and otherwise treatment resistant patients $[10,12]$.

\section{Second- and third-generation antipsychotics}

\section{Risperidone}

Risperidone acts through a dopamine D2 receptor and 5-HT2 receptor antagonism [126]. It is one of the best studied antipsychotics for the treatment of tics [16].

Three systematic reviews $[8,9,90]$ describing the effect of risperidone on tics have been published since 2011, indicating that risperidone is effective in reducing tics. The most recent meta-analysis (including also Chineselanguage RCTs) of risperidone as treatment for TS pointed to a standardized mean difference compared with placebo of 3.47 (95\% CI [0.37-6.87]) [6]. One RCT [127] in 60 subjects compared the effects of aripiprazole and risperidone in children and adolescents over a 2-month period, with the conclusion that both medications were tolerated well, with equal effectiveness and similar adverse effects, including increased appetite in over $25 \%$ of the participants for either agent. Risperidone, in contrast, was superior in improving the patients' social functioning in the short term.

In terms of adverse effects, $35 \%$ of children with tics using risperidone developed EPS in a prospective longitudinal study on antipsychotic safety monitoring [128]. Risperidone-related weight gain seems to follow a pattern with a significant increase of body mass index (BMI) in the first month, followed by only a slow increase thereafter [129, 130]. Increase of prolactin levels was present in $41 \%$ of the children treated for tics [128].

\section{Aripiprazole}

Aripiprazole reduces dopaminergic neurotransmission through D2 partial agonism [131-133]. Thus, it modulates neurotransmission in dopaminergic (mainly mesolimbic and mesocortical) pathways. In addition, it is a partial 5-HT1A agonist and a 5-HT2A antagonist [131-134]. Aripiprazole has become a frequently used agent for the treatment of tics due to its good effectiveness on tics and less prominent adverse effects [50, 69, 72, 73, 111, 135].

Until 2011, the use of aripiprazole was only reported in case studies, retrospective observational studies, and openlabel trials [51]. Thereafter, aripiprazole has become the main focus in research on the pharmacological treatment of tics: seven systematic reviews including five meta-analyses or combinations of the two $[6,8,66,68,69,71,72]$ and two placebo controlled RCTs [136, 137] have been published since 2011. All publications consistently documented the effectiveness of aripiprazole in reducing tics, with similar effect sizes as compared to other dopamine-modulating agents, such as haloperidol and risperidone [6, 127, 138]. The most recent meta-analysis (including also Chineselanguage RCTs) pointed to a standardized mean difference of aripiprazole compared with placebo of 4.74 (95\% CI [1.06-8.67]) [6]. Moreover, there is some evidence from an open-label study that aripiprazole may also have a positive effect on co-existing conditions, such as depression, anxiety, and auto-aggression in adults with TS [135], as well as on social adjustment and parental stress [139]. However, it may have an unfavorable effect on complex learning tasks [140].

Aripiprazole has a more favorable profile of adverse effects compared to other antipsychotics with lower risk of akathisia and other EPS, anxiety, constipation, dizziness, headache, insomnia, nausea, and vomiting in patients with TS $[6,8,111,137]$. Based on a study in children and adolescents with TS, aripiprazole has a safer cardiovascular profile than pimozide, with a lower frequency of QTc prolongation [125]. Importantly, aripiprazole is less sedating than most other antipsychotics in patients with psychosis [141]. However, more recent literature showed a mean EPS incidence of $17.1 \%$ (95\% CI 12.8-22.3\%) in children and adolescents with a variety of psychiatric disorders treated with aripiprazole [142]. As described in other antipsychotic agents, children gain more weight due to aripiprazole than adolescents and adults [120, 137], but among all antipsychotics aripiprazole has a relatively favorable metabolic profile [143].

\section{Benzamides}

\section{Tiapride}

Tiapride, a benzamide with low antipsychotic action, acts as a selective dopamine antagonist at dopamine D2 and D3 
receptors. Despite its frequent use, particularly in German speaking Europe, the evidence on its effectiveness in the treatment of tics in controlled trials is still sparse [52, 144]. While tiapride is not available in the US [145], in recent years, there was a growing interest in this agent in other countries, such as China $[6,138]$ and two Chinese guidelines recommended tiapride as first-line medication (Chinese medical association [11]; Chinese Child Neurology Society [12]).

Since 2011, there has been one new English-language RCT [138] and more than 10 Chinese-language RCTs (not cited here, for an overview see [6]) — the first ones after the small scale RCT from 1988 [146]. Since 2011, five reviews including one meta-analysis $[6,8,69,71,72]$ covered also tiapride for the treatment of tics, while others did not even mention tiapride [40, 58]. The most recent network metaanalysis of 14 available RCTs (all conducted in China) did not find that tiapride is significantly better than placebo [6], which is in contrast to the recommendations of the AAN [3] and both Chinese $[11,12]$ guidelines based on RCTs. Interestingly, a recent study on therapeutic drug monitoring in 49 pediatric patients $(83.7 \%$ male, mean age $=12.5$ years) found a positive correlation between tiapride dose (median $6.9 \mathrm{mg} /$ $\mathrm{kg}$, range $0.97-19.35$ ) and serum concentration albeit with marked inter-individual variability. The variation in dose explained $57 \%$ of the inter-patient variability in tiapride serum concentrations; age, sex, and concomitant medication did not contribute to the variability. Tics improved in $83.3 \%$ of the patients. $27.1 \%$ of the patients had mild or moderate adverse effects [147].

A meta-analysis comparing the effects of different antipsychotics in TS [6] demonstrated that the most common adverse effects in patients with TS treated with tiapride are dizziness, nausea, and dry mouth, while EPS are rare [138, 145]. However, quite rarely EPS might be observed in case of a steep drug increase in the initial phase of treatment or with irregular drug intake. Of note, tiapride can be successfully used to treat (tardive) dyskinesias due to antipsychotics $[145,148]$.

\section{Noradrenergic agents}

Noradrenergic agents such as clonidine and guanfacine are more commonly used in children and adolescents than in adults and mainly in those patients with a combination of ADHD and mild tics given their efficacy in treating ADHD symptoms in addition to tics.

\section{Clonidine}

For the treatment of tics, clonidine, an $\alpha-2$ adrenergic agonist, has been used more commonly in America than in Europe [111] and is available as an oral and transdermal preparation. A systematic review [8] concluded that the balance of clinical benefits to harm favors the $\alpha-2$ adrenergic receptor agonists clonidine and guanfacine (based on four studies with low risk of bias dating before 2011). However, the authors reported substantial heterogeneity with studies with transdermal application of clonidine being less effective compared to oral administration. The most recent metaanalysis of clonidine as treatment for TS pointed to a small standardized mean difference compared with placebo of 0.29 (95\% CI [0.12-0.47]) [90]. This meta-analysis [90] indicated that the effect size of $\alpha-2$ adrenergic agonist on tic reduction is much larger in children with tics plus ADHD (95\% CI: 0.36-1.01) than in individuals with tics without ADHD (95\% CI: - 0.06-0.36). Moreover, a prospective, open trial in 41 children and adolescents in whom previous treatment with a D2-dopamine receptor antagonist was ineffective or not well tolerated indicated a response rate of $63 \%$ after 12 weeks of treatment with a clonidine transdermal patch [149]. Unfortunately, the authors did not report effects on co-existing ADHD.

A systematic review of adverse effects of $\alpha-2$ adrenergic agonists in children and adolescents with ADHD demonstrated hypotension, bradycardia, and sedation with clonidine as well as guanfacine [150]. Abrupt withdrawal of $\alpha-2$ adrenergic agonists may cause rebound hypertension [151]. Therefore, blood pressure and pulse should be measured at baseline and monitored during dose adjustments and followup. In addition, monitoring of symptoms suggestive of cardiovascular problems (e.g., exercise intolerance, dizziness, and syncope) is recommended [152].

\section{Guanfacine}

Guanfacine, another $\alpha-2$ adrenergic agonist, may reduce tics and improve ADHD symptoms in children and adolescents. However, in a recently published small-scale randomized double-blind placebo-controlled trial in children and adolescents $(50 \%$ of the guanfacine, $22 \%$ of the placebo group suffered from co-existing ADHD) [153], guanfacine was not more efficacious than placebo in reducing tics. Previously, a meta-analysis of guanfacine as treatment for TS pointed to a standardized mean difference compared with placebo of 0.54 (95\% CI [0.06-1.14]) [90].

The most common adverse effects of guanfacine are sedation, headache, fatigue, dizziness, irritability, upper abdominal pain, and nausea, with sedation and fatigue usually emerging within the first 2 weeks of dosing and then generally remitting [154]. Guanfacine may induce mania in children with a history or family history of bipolar disorder $[155,156]$. Especially the extended release formulation of guanfacine may induce QTc prolongation [150], and therefore, patients should be monitored accordingly [3]. 


\section{Other agents}

\section{Cannabis-based medicines}

First reports of successful self-medication with the exocannabinoid cannabis date back to 1988 [157]. During the last years, more and more, mostly adult patients use cannabis as a self-medication and report beneficial effects $[86,158]$. Indeed, there is an increasing number of case reports and small studies suggesting that cannabis-based medicines including cannabis flowers, cannabis extracts, and pure THC (dronabinol) might be effective in the treatment of tics and co-existing symptoms including ADHD. Since 2011, no new RCTs have been published. A recent meta-analysis on the two available small-scale RCTs (combined $n=41$ ) demonstrated no significant benefit of THC compared to placebo as treatment of TS [159]. No serious adverse reactions were reported either, with only mild adverse reactions including dizziness, tiredness, and dry mouth [160, 161].

\section{Botulinum toxin}

In addition to the use of pharmacological agents with systemic effects, there is some evidence for the efficacy of botulinum toxin injections to treat persistent well-localized motor and, sometimes, vocal tics by temporarily weakening the associated muscles, through the inhibition of acetylcholine release from peripheral motor nerve terminals. In European practice this approach is limited to older adolescents and adults in patients with insufficient response to other treatments. According to the AAN guidelines on TS [3] botulinum toxin as local application is probably more likely than placebo to reduce tics. This judgement as well as several reviews after 2011 on botulinum toxin in TS [74-85] are based on the only published randomized crossover trial of botulinum toxin injection versus placebo for the treatment of simple motor tics from 2001 conducted in 20 adolescents and adults [162]. Adverse reactions associated with botulinum toxin may include temporary soreness and mild muscle weakness including hypophonia when used in the throat region to treat disturbing vocal tics [163].

\section{Topiramate}

Topiramate is a sulfamate modified fructose diacetonide with unknown mechanisms of action. There have been no new English-language RCTs, since a 12-week randomized controlled trial of topiramate versus placebo published in 2010 that showed superior effects of topiramate compared to placebo in 29 children and adults with TS [164]. However, the authors of a recent meta-analysis [96] summarizing a total of 15 studies from China involving 1070 participants aged 2-17 years concluded that topiramate is a promising medication with good efficacy and tolerability for children with TS compared to haloperidol and tiapride.

While generally well tolerated at low doses $(25-150 \mathrm{mg} /$ day) it may cause a variety of adverse effects, including cognitive and language problems, aggression or mood swings, paresthesia, nausea, sweating problems, and decreased appetite [165].

\section{Pharmacological treatment of tics in the context of co-existing psychiatric conditions}

People with TS often suffer from co-existing problems, such as ADHD, OCD, mood disorders, anxiety, oppositional defiant disorder, and impulse control disorders (see Part I of this issue). The distress and burden associated with these co-existing conditions is often more significant to patients $[166,167]$ than the tics themselves. Although data are still limited [168], below, we present a possible approach for the treatment of co-existing psychiatric conditions in patients with TS.

\section{Attention-deficit/hyperactivity disorder (ADHD)}

ADHD is prevalent in 30-50\% of referred children with TS and is strongly associated with functional impairment [166, 167]. ADHD symptoms typically improve in adolescence [169], but some adults with TS may still need continued treatment for this co-existing disorder [170]. Several pharmacological trials have assessed medication for co-existing ADHD in TS. Across studies, therapeutic doses of methylphenidate, dextroamphetamine, clonidine, guanfacine, and atomoxetine reduce ADHD symptoms as well as tics in patients with TS, probably through allowing a better self-regulatory control [99]. The $\alpha-2$ agonists clonidine and guanfacine are among the agents with the most favorable efficacy-versus-adverse events ratio but effect sizes vary $[8,9,90]$. While earlier studies described that stimulants exacerbated tics or even caused first tics in some individuals [171], more recent studies demonstrated that tics do not emerge or worsen under the treatment with short-acting [172, 173] or short- and long-acting stimulants [174]; however, a transient increase may occur. On the contrary, a mild reduction of tics may occur in the treatment with methylphenidate in children with tics plus ADHD [99]. In rare cases with a persistent increase of tics after introducing a stimulant, the use of atomoxetine may be a viable alternative, which may in general have a positive effect on tics via a reduction of ADHD symptoms [3, 103]. When treating with psychostimulants, some adverse events should be taken into 
consideration: sleeplessness, nervousness, headache, blood pressure raise, loss of appetite, weight loss, and gastrointestinal complaints. According to an open-label study aripiprazole results in an effective reduction of tics, but affects ADHD symptoms only moderately [175].

\section{Obsessive-compulsive disorder (OCD)}

Obsessive-compulsive behaviors are very common in people with TS, presenting frequently sensory-motor phenomena, such as urges and just-right feelings that may overlap with tics. Diagnostic criteria for OCD are met in up to $50 \%$ of people with tics $[105,176]$. Trial data for OCD treatment in children (POTS II) suggest that individuals with tics respond as well to selective serotonin reuptake inhibitors (SSRIs) as those without tics and respond equally well to cognitive behavioral interventions [177] in contrast to an earlier study indicating a less favorable response to sertraline [178]. In addition, for OCD co-existing with TS, behavioral therapy approaches are the first-line treatment [3]. Small observational studies suggest that individuals without sufficient treatment response to behavioral therapy alone may benefit from an added SSRI [105]. Some fixed-dose trials of SSRIs showed that in the treatment of OCD higher doses are significantly superior to lower ones; there is, however, an expected greater adverse effect burden with higher doses of SSRIs [179]. It is worth noting that SSRIs may not only reduce OCD symptoms but also alter overall affect, anxiety, and stress sensitivity, which may lead to better selfregulation and tic suppression. However, this has not been documented in an RCT.

In treatment resistant OCD in the context of TS, antipsychotic augmentation of treatment with SSRI using aripiprazole and risperidone may be considered [180]; the subgroup of patients with OCD and co-existing tics had a particularly beneficial response to treatment with antipsychotic augmentation in a meta-analysis [179]. However, it is important to keep in mind the limited evidence base and the need for drug safety monitoring, as pointed out in an observational study including children with tic-related OCD [180] as well as a meta-analysis including adults with OCD (without tics) [181].

\section{Other co-existing psychiatric conditions}

In addition to ADHD and OCD, people with TS are at risk of developing depression, anxiety disorders, oppositional defiant disorder, rage attacks, and mood disorders [176]. Co-existing mood disorders are more often seen in adolescents and adults than in children and in those with greater tic severity [3]. It is worth noting that there is an increased risk of suicidal ideation, suicide attempts, and suicide in people with TS, also when statistically controlling for other coexisting psychiatric conditions [182]. Unfortunately, there are no treatment studies to guide the clinician in treating these co-existing problems.

Guanfacine and clonidine can be effective in individuals with co-existing impulse control disorder [90]. Aripiprazole and risperidone are useful for co-existing irritability and aggressive behaviors [183-186].

Tics and stereotyped movements are frequent in Autism Spectrum Disorder, and a clear diagnostic distinction between them may be challenging to establish $[28,106]$. Treatment with risperidone or fluoxetine may be considered in cases with stereotypies that are debilitating and involving harm and injury to self and others [187].

\section{Clinical recommendations for the pharmacological treatment of TS}

Decisions about treatment of TS should be based on a thorough and broad diagnostic process (see Part I of this issue). Behavioral therapy approaches are recommended as first line treatment, based on assumed better tolerability of behavioral therapy, because behavioral approaches might strengthen the patients' self-regulatory control $[3,188]$ (see Part V of this issue). However, these are not always locally accessible (a major factor in many countries) or feasible because of low introspective ability in young age or low IQ, or due to low motivation or ability to invest time and effort required for practicing in behavioral therapy. For individuals with clear impairments associated with their tics or with a preference for pharmacotherapy, after psychoeducation pharmacologic interventions may be considered alone or in addition to behavioral therapy. This concerns especially situations, where tics impair quality of life and cause subjective discomfort (e.g., pain or injury) or when tics result in sustained social problems (e.g., social isolation or bullying) or cause functional interference (e.g., impairment of academic achievements) [111]. In addition, pharmacological treatment acts faster, because prescription, dispensing, and intake of first dose are easier than planning and commencing behavioral therapy. Moreover, first treatment effects are often seen within a few days, while after behavioral therapy first beneficial effects in most cases cannot be observed until after a few weeks. Therefore, pharmacotherapy may be preferred in situations, where a rapid tic reduction is urgently required.

The waxing and waning course (including its time course) of the tics in each individual should be taken into account when deciding on starting therapy and when evaluating treatment effects.

Independently from the individual factors that result in the decision to start pharmacological treatment of tics it is important to inform patients and their parents about what can be achieved by this kind of treatment to avoid too high expectations. On average, a tic reduction of $50 \%$ can 
be expected. However, some patients report a reduction of $90 \%$, while others feel no or only minimal improvement.

The decision to propose a treatment with a specific agent is an individual choice made by the clinician, in collaboration with the patient and family and depends on the patient's needs, preferences, and priorities as well as on the physician's preferences, experience, and local regulatory requirements.

During the last decades, several agents have been suggested and used as rational medication for the treatment of tics. Based on evidence from RCTs and on clinical experience aripiprazole, tiapride, and risperidone for TS as well as clonidine and guanfacine for TS and co-existing ADHD are the best established options, all on the basis of off-label use. In general, we recommend a "start low, go slow" drug up-titration, meaning that the therapy should be initiated with the lowest dose possible and gradually increased. It is important to bear in mind that the antipsychotic dosages normally used for the treatment of tics are considerably lower than those used to treat psychotic disorders.

Depending on its individual receptor binding profile, each agent bears the risk of specific adverse effects. Therefore, not only effectiveness but also potential adverse effects of each agent should be taken into consideration when deciding about the most suitable agent for a patient with TS. Most pharmacological treatments discussed in these guidelines have well known adverse effects, including weight gain, drug-induced movement disorders, elevated prolactin levels, sedation, and effects on heart rate, blood pressure, and electrocardiograms. Therefore, careful monitoring of adverse events is recommended (see Table 2). In case of treatment discontinuation, gradual tapering off antipsychotic medications is recommended to avoid withdrawal dyskinesias [3].

An important aspect when choosing an agent for a patient is also the presence of co-existing conditions. Often, the co-existence of ADHD or OCD, as well as mood, anxiety, or impulse control disorders may be more disturbing to the patient than the tics [167] and may thus have important implications for the choice of medication. Evidence for those choices is still limited, but this differentiation already presents an important step towards an individualized approach to medication in TS.

While the evidence-based practice recommendations of the AAN did not present a hierarchical recommendation what agent should be given first, the ESSTS survey indicates that aripiprazole is now the most commonly used agent for the pharmacological treatment of TS for both age groups (children and adolescents, adults). This may be the result of several factors, one being the unique pharmacological profile as a dopamine partial agonist [189], but also the availability of several RCTs with sufficient sample sizes that document a favorable benefit-risk ratio, predominantly being the result of its positive profile of adverse effects [69, 70, 72]. Positron emission tomography studies demonstrated that the clinical effect of an antipsychotic emerges when more than $65 \%$ of striatal dopamine D2 receptors are blocked, and EPSs become apparent when the receptor blockade exceeds $80 \%$ [190]. Thus, in the ideal antipsychotic therapy (antipsychotic efficacy without EPSs), about $70 \%$ of striatal dopamine D2 receptors are blocked. When tight antipsychotics bind 70\% of $\mathrm{D} 2$ receptors, the remaining $30 \%$ are available for endogenous dopamine to bind. This means that dopaminergic transmission is reduced to $30 \%$, and both tonic/phasic components are suppressed equally. In one study, aripiprazole was effective at a dose of up to $20 \mathrm{mg}$, where $10 \%$ or fewer D2 receptors were available for endogenous dopamine to bind; however, EPSs did not appear, because aripiprazole exerted a partial dopaminergic agonistic activity [191].

Tiapride, the second most commonly prescribed agent in children and adolescents with tics, especially in Germany, has a similar working mechanism as aripiprazole, showing a maximum of $80 \%$ of dopamine receptor occupation even in the presence of excess tiapride concentrations [145]. Interestingly, for two of the most commonly used agents according to the ESSTS survey there is evidence from pharmacodynamic studies explaining their low (aripiprazole) or very low (tiapride) potential for EPS compared to haloperidol [69, 70, 138, 145].

Another recommended antipsychotic agent, risperidone, actually has a good evidence base, but is associated with weight gain and metabolic adverse effects.

The European survey documented that noradrenergic agents are the third most given agents regarding both age groups together. Importantly, noradrenergic agents have a low effectiveness in patients with tics only, but this substantially increases in patients (particularly children and adolescents) with the combination of tics and ADHD, both for reducing tics and symptoms of ADHD [8, 90]. Therefore, we recommend noradrenergic agents as first line treatment of mild to moderate tics in patients with co-existing ADHD, but less in those without co-existing ADHD as there they have only minimal benefits. However, in some patients with mild tics only, noradrenergic agents may be more acceptable than antipsychotics, based on more favorable adverse effects.

In treatment resistant cases, treatment with agents with sometimes a still limited evidence base and less frequently prescribed by ESSTS experts might be considered. Reasonable choices include antipsychotics including haloperidol, pimozide, quetiapine, sulpiride, and amisulpiride as well as cannabisbased medicines, topiramate, and botulinum toxin injections.

Haloperidol is still relatively often used in adults with TS, but rarely mentioned by any ESSTS expert as treatment option for children and adolescents. Its declined use can be explained by its unfavorable adverse effect profile compared to other antipsychotics, even though haloperidol is the only officially licensed substance for TS and tics in Europe, and has a long tradition and established efficacy in the treatment of TS, with relatively low costs. 
Table 2 Most common medications for Tourette syndrome and other chronic tic disorders

\begin{tabular}{|c|c|c|c|c|c|c|c|}
\hline Medication & Indication & $\begin{array}{l}\text { Start dosage } \\
(\mathrm{mg})\end{array}$ & $\begin{array}{l}\text { Therapeutic } \\
\text { range per day } \\
(\mathrm{mg})\end{array}$ & Effect size* & $\begin{array}{l}\text { Confidence in } \\
\text { the quality of } \\
\text { the evidence** }\end{array}$ & $\begin{array}{l}\text { Very common } \\
\text { adverse events } \\
(>10 \%)^{* * *}\end{array}$ & $\begin{array}{l}\text { Physical and labo- } \\
\text { ratory Examina- } \\
\text { tions at the start } \\
\text { and at follow-ups }\end{array}$ \\
\hline \multicolumn{8}{|c|}{$\alpha-2$ adrenergic agonists } \\
\hline Clonidine & $\mathrm{ADHD} / \mathrm{TS}$ & 0.025 & $\begin{array}{l}0.025-0.3 \\
\text { (titrated } \\
\text { according to } \\
\text { BP and HR) }\end{array}$ & $\begin{array}{l}0.29(0.12-0.47) \\
\quad[90]\end{array}$ & Moderate & $\begin{array}{l}\text { Dizziness, } \\
\text { orthostatic } \\
\text { hypotension, } \\
\text { dry mouth }\end{array}$ & $\begin{array}{l}\text { Blood pressure, } \\
\text { ECG }\end{array}$ \\
\hline \multicolumn{8}{|c|}{ First generation antipsychotics } \\
\hline Haloperidol & $\mathrm{TS}$ & $0.25-0.5$ & $0.25-3.0$ & $\begin{array}{l}3.20(0.14-6.52) \\
\quad[6]\end{array}$ & Moderate & $\begin{array}{l}\text { Agitation, } \\
\text { insomnia, EPS, } \\
\text { hyperkinesia, } \\
\text { headache }\end{array}$ & ECG, weight \\
\hline Pimozide & TS & $0.5-1.0$ & $1.0-4.0$ & $\begin{array}{c}0.42(-0.07- \\
0.90)[6]\end{array}$ & Low & $\begin{array}{l}\text { Dizziness, } \\
\text { somnolence, } \\
\text { hyperhidrosis, } \\
\text { nocturia }\end{array}$ & ECG, weight \\
\hline \multicolumn{8}{|c|}{ Newer antipsychotics } \\
\hline Aripiprazole & $\mathrm{TS}$ & 2.50 & $2.5-30$ & $\begin{array}{l}4.74(1.06-8.67) \\
\quad[6]\end{array}$ & Moderate & $\begin{array}{l}\text { Somnolence, } \\
\text { sedation }\end{array}$ & $\begin{array}{l}\text { Weight, blood } \\
\text { lipids, and } \\
\text { glucose }\end{array}$ \\
\hline Risperidone & TS/DBD & 0.25 & $0.25-3.0$ & $\begin{array}{l}3.47(0.37-6.87) \\
\quad[6]\end{array}$ & Moderate & $\begin{array}{l}\text { Insomnia, } \\
\text { sedation/ } \\
\text { somnolence, } \\
\text { parkinsonism, } \\
\text { headache }\end{array}$ & $\begin{array}{l}\text { Weight, prolactin, } \\
\text { blood lipids, and } \\
\text { glucose }\end{array}$ \\
\hline \multicolumn{8}{|l|}{ Benzamides } \\
\hline Tiapride & $\mathrm{TS}$ & $\begin{array}{l}50-100(2 \mathrm{mg} / \\
\mathrm{kg})\end{array}$ & $\begin{array}{l}100-600 \\
(2-10 \mathrm{mg} / \mathrm{kg})\end{array}$ & $\begin{array}{c}0.47(-3.89- \\
5.06)[6]\end{array}$ & Moderate & $\begin{array}{l}\text { Hyperprolactine- } \\
\text { mia*, sleepi- } \\
\text { ness, insomnia, } \\
\text { agitation, } \\
\text { impassivity, } \\
\text { vertigo, head- } \\
\text { ache }\end{array}$ & $\begin{array}{l}\text { ECG, weight, } \\
\text { prolactin }\end{array}$ \\
\hline \multicolumn{8}{|l|}{ Others } \\
\hline $\begin{array}{l}\text { Botulinum } \\
\text { toxin }\end{array}$ & $\mathrm{TS}$ & $\begin{array}{l}\text { Vocal tics: } 1-2.5 \\
\text { U } \\
\text { Motor tics: } \\
50-75 \mathrm{U}\end{array}$ & $\begin{array}{l}1-2.5 \\
75-250\end{array}$ & $\begin{array}{l}1.27(0.51-2.03) \\
\quad[4]\end{array}$ & Moderate & $\begin{array}{l}\text { Weakness of } \\
\text { the injected } \\
\text { muscles }\end{array}$ & \\
\hline
\end{tabular}

$D B D$ disruptive behavior disorder; $O C B$ obsessive-compulsive behavior; $T S$ Tourette syndrome; $A D H D$ attention-deficit/hyperactivity disorder; $B M I$ body mass index; $E P S$ extrapyramidal symptoms; $B P$ Blood pressure; $H R$ heart rate; $E C G$ electrocardiogram

Information on the adverse effects stems from the official Summaries of product characteristics, if no very common Adverse Events ( $>10 \%)$, *standardized mean difference compared with placebo (including 95\% confidence interval; positive number pointing to efficacy) according to the most recent meta-analysis (for botulinum toxin based on a single study), as referenced $* *$ based on the Grading of Recommendations, Assessment, Development and Evaluations (GRADE) as reported by AAN [4] ***common Adverse Events $(<10 \%$ and $>1 \%)$ are provided

\section{Current limitations and future directions}

In the light of the limited existing evidence several questions remain unanswered: most importantly, the effectiveness of combinations of behavioral therapy with pharmacological treatment and of different agents needs further trials. Studies directly comparing different agents or combinations of agents in TS are rare, and there is currently only one study
[192] available that compared pharmacological treatment with behavior therapy, yielding equal effects within a study period of 10 weeks. Moreover, the study periods of published trials on pharmacological treatment of TS were quite short, e.g., in view of the natural waxing and waning course of tics in TS. In addition, research should be conducted on treatment sequencing and decision-making and for whom particular sequences of treatment are most effective [3]. 
Another area in need of further evidence is the treatment of patients with co-existing conditions. Moreover, questions around how to deal with treatment refractoriness remain unanswered [193]. The risk of adverse events when using specific agents needs further exploration, e.g., sudden death due to QTc prolongation [116], hyperprolactinemia and its consequences [109], and weight gain [128]. In addition, the questions of optimal treatment duration, as well as longterm outcome after discontinuation of a pharmacological treatment of tics remain unanswered. These important points for the pharmacotherapy of TS are still open to discussion due to a non-existent or too small base of evidence and are important areas for future research. Unfortunately, the number of new agents that might be effective as treatment of TS is limited. Perhaps most promising are the Chinese herbal medicine products 5-ling granule and Ningdong granule, which were classified as compounds showing moderate confidence in evidence of treatment effects according to the AAN guidelines, based on well-powered RCTs conducted in China. However, these products are currently not available to clinicians on the European market. One final future step to improve pharmacological treatment of TS would be precision medicine as well as personalized medicine [194] by prior genetic testing or the use of other neurobiological markers [195]. This approach, however, is still an aspiration for neuropsychiatric disorders, such as TS.

Acknowledgements This work was supported by a grant from the Deutsche Forschungsgemeinschaft (DFG; FOR 2698).

Funding Open Access funding enabled and organized by Projekt DEAL.

\section{Declarations}

Conflict of interest VR has received payment for consulting and writing activities from Lilly, Novartis, and Shire Pharmaceuticals, lecture honoraria from Lilly, Novartis, Shire Pharmaceuticals, and Medice Pharma, and support for research from Shire Pharmaceuticals and Novartis. He has carried out clinical trials in cooperation with the Novartis, Shire, Servier and Otsuka companies. KMV has received financial or material research support from the EU (FP7-HEALTH-2011 No. 278367, FP7-PEOPLE-2012-ITN No. 316978), the German Research Foundation (DFG: GZ MU 1527/3-1), the German Ministry of Education and Research (BMBF: 01KG1421), the National Institute of Mental Health (NIMH), the Tourette Gesellschaft Deutschland e.V., the Else-Kröner-Fresenius-Stiftung, and Abide Therapeutics, Almirall Hermal GmbH, GW pharmaceuticals, Lundbeck, Syneos Health, and Therapix Biosciences Ltd. She has received consultant's honoraria from Abide Therapeutics, Allmiral, Boehringer Ingelheim International GmbH, Bionorica Ethics GmbH, CannaMedical Pharma GmbH, Canopy Grouth, Columbia Care, CTC Communications Corp., Eurox Deutschland GmbH, Global Praxis Group Limited, IMC Germany, Lundbeck, Resalo Vertrieb GmbH, Sanity Group, STADAPHARM $\mathrm{GmbH}$, Synendos Therapeutics AG, and Tilray. She is/was a consultant or advisory board member for Abide Therapeutics, The Academy of Medical Cannabis Limited, Alirio, Aphria Deutschland GmbH, CannaMedical Pharma GmbH, Bionorica Ethics GmbH, CannaXan
GmbH, Canopy Growth, Columbia Care, CTC Communications Corp., IMC Germany, Leafly Deutschland GmbH, Lundbeck, Nuvelution TS Pharma Inc., Resalo Vertrieb GmbH, Sanity Group, Syqe Medical Ltd., Therapix Biosciences Ltd., Tilray, and Wayland Group. She has received speaker's fees from Aphria Deutschland GmbH, Cogitando GmbH, Emalex, Eurox Deutschland GmbH, Ever pharma GmbH, PR Berater, Spectrum Therapeutics GmbH, Tilray, and Wayland Group. She has received royalties from Medizinisch Wissenschaftliche Verlagsgesellschaft Berlin, Elsevier, and Kohlhammer. She served as a Guest editor for Frontiers in Neurology on the research topic "The neurobiology and genetics of Gilles de la Tourette syndrome: new avenues through large-scale collaborative projects", and is Associate editor for "Cannabis and Cannabinoid Research", Editorial Board Member for "Medical Cannabis and Cannabinoids" and "MDPI-Reports", and scientific board member for "Zeitschrift für Allgemeinmedizin". CG is supported by VolkswagenStiftung (Freigeist Fellowship) and served ad hoc as advisory board for Lundbeck. AC is author of the book "Pharmacological Treatment of Tics". Cambridge University Press, 2020. $\mathrm{PJH}$ has received a payment as member of an advisory board meeting of Shire Pharmaceuticals and has carried out a clinical trial in cooperation with Servier. All other authors declare that they have no conflict of interests.

Open Access This article is licensed under a Creative Commons Attribution 4.0 International License, which permits use, sharing, adaptation, distribution and reproduction in any medium or format, as long as you give appropriate credit to the original author(s) and the source, provide a link to the Creative Commons licence, and indicate if changes were made. The images or other third party material in this article are included in the article's Creative Commons licence, unless indicated otherwise in a credit line to the material. If material is not included in the article's Creative Commons licence and your intended use is not permitted by statutory regulation or exceeds the permitted use, you will need to obtain permission directly from the copyright holder. To view a copy of this licence, visit http://creativecommons.org/licenses/by/4.0/.

\section{References}

1. Roessner V, Rothenberger A, Rickards H, Hoekstra PJ (2011) European clinical guidelines for Tourette syndrome and other tic disorders. Eur Child Adolesc Psychiatry 20:153-154. https:// doi.org/10.1007/s00787-011-0165-5

2. Farag M, Stern JS, Simmons H, Robertson MM (2015) Serial pharmacological prescribing practices for tic management in Tourette syndrome. Hum Psychopharmacol 30:435-441. https:// doi.org/10.1002/hup.2495

3. Pringsheim T, Okun MS, Müller-Vahl K et al (2019) Practice guideline recommendations summary: treatment of tics in people with Tourette syndrome and chronic tic disorders. Neurology 92:896-906. https://doi.org/10.1212/WNL.0000000000007466

4. Pringsheim T, Holler-Managan Y, Okun MS et al (2019) Comprehensive systematic review summary: treatment of tics in people with Tourette syndrome and chronic tic disorders. Neurology 92:907-915. https://doi.org/10.1212/WNL.0000000000007467

5. Hollis C, Pennant M, Cuenca J et al (2016) Clinical effectiveness and patient perspectives of different treatment strategies for tics in children and adolescents with Tourette syndrome: a systematic review and qualitative analysis. Health Technol Assess 20:1-450. https://doi.org/10.3310/hta20040

6. Yang C, Hao Z, Zhang L-L et al (2019) Comparative efficacy and safety of antipsychotic drugs for tic disorders: a systematic review and Bayesian network 
meta-analysis. Pharmacopsychiatry 52:7-15. https://doi.org/ 10.1055/s-0043-124872

7. Zhang Z, Yang C, Zhang L-L et al (2018) Pharmacotherapies to tics: a systematic review. Oncotarget 9:28240-28266. https:// doi.org/10.18632/oncotarget. 25080

8. Whittington C, Pennant M, Kendall T et al (2016) Practitioner review: treatments for Tourette syndrome in children and young people-a systematic review. J Child Psychol Psychiatry 57:988-1004. https://doi.org/10.1111/jcpp.12556

9. Waldon K, Hill J, Termine C et al (2013) Trials of pharmacological interventions for Tourette syndrome: a systematic review. Behav Neurol 26:265-273. https://doi.org/10.3233/ BEN-2012-120269

10. Pringsheim T, Doja A, Gorman D et al (2012) Canadian guidelines for the evidence-based treatment of tic disorders: pharmacotherapy. Can J Psychiatry 57:133-143

11. Neurological Group, Branch of Pediatrics, Chinese Medical Association (2017) Expert consensus on diagnosis and treatment of tic disorder in children 2017. Chin J Appl Clin Pediatr 32:1137-1140

12. Liu Z-S, Cui Y-H, Sun D et al (2020) Current status, diagnosis, and treatment recommendation for tic disorders in China. Front Psychiatry. https://doi.org/10.3389/fpsyt.2020.00774

13. Cavanna AE (2018) Gilles de la Tourette syndrome as a paradigmatic neuropsychiatric disorder. CNS Spectr 23:213-218. https://doi.org/10.1017/S1092852918000834

14. Cavanna AE, Seri S (2013) Tourette's syndrome. BMJ 347:f4964. https://doi.org/10.1136/bmj.f4964

15. Cavanna AE, Termine C (2012) Tourette syndrome. Adv Exp Med Biol 724:375-383. https://doi.org/10.1007/978-1-46140653-2_28

16. Deeb W, Malaty IA, Mathews CA (2019) Tourette disorder and other tic disorders. Handb Clin Neurol 165:123-153. https:// doi.org/10.1016/B978-0-444-64012-3.00008-3

17. Efron D, Dale RC (2018) Tics and Tourette syndrome. J Paediatr Child Health 54:1148-1153. https://doi.org/10.1111/jpc. 14165

18. Ganos C (2016) Tics and Tourette's: update on pathophysiology and tic control. Curr Opin Neurol 29:513-518. https://doi. org/10.1097/WCO.0000000000000356

19. Ganos C, Martino D, Pringsheim T (2017) Tics in the pediatric population: pragmatic management. Mov Disord Clin Pract 4:160-172. https://doi.org/10.1002/mdc3.12428

20. Ganos C, Martino D (2015) Tics and Tourette syndrome. Neurol Clin 33:115-136. https://doi.org/10.1016/j.ncl.2014.09.008

21. Gravino G (2013) Gilles de la Tourette syndrome. Ann Clin Psychiatry 25:297-306

22. Greydanus DE, Tullio J (2020) Tourette's disorder in children and adolescents. Transl Pediatr 9:S94-S103. https://doi.org/ 10.21037/tp.2019.09.11

23. Gunduz A, Okun MS (2016) A review and update on Tourette syndrome: where is the field headed? Curr Neurol Neurosci Rep 16:37. https://doi.org/10.1007/s11910-016-0633-x

24. Hallett M (2015) Tourette syndrome: update. Brain Dev 37:651-655. https://doi.org/10.1016/j.braindev.2014.11.005

25. Jankovic J (2015) Therapeutic developments for tics and myoclonus. Mov Disord 30:1566-1573. https://doi.org/10.1002/ mds. 26414

26. Macerollo A, Martino D (2016) What is new in tics, dystonia and chorea? Clin Med (Lond) 16:383-389. https://doi.org/10. 7861/clinmedicine.16-4-383

27. McNaught KSP, Mink JW (2011) Advances in understanding and treatment of Tourette syndrome. Nat Rev Neurol 7:667-676. https://doi.org/10.1038/nrneurol.2011.167
28. Mills S, Hedderly T (2014) A guide to childhood motor stereotypies, tic disorders and the Tourette spectrum for the primary care practitioner. Ulster Med J 83:22-30

29. Mittal SO (2020) Tics and Tourette's syndrome. Drugs Context. https://doi.org/10.7573/dic.2019-12-2

30. Novotny M, Valis M, Klimova B (2018) Tourette syndrome: a mini-review. Front Neurol 9:139. https://doi.org/10.3389/fneur. 2018.00139

31. Plessen KJ (2013) Tic disorders and Tourette's syndrome. Eur Child Adolesc Psychiatry 22(Suppl 1):S55-S60. https://doi.org/ 10.1007/s00787-012-0362-x

32. Pringsheim T (2013) Tourette syndrome and other tic disorders of childhood. Handb Clin Neurol 112:853-856. https://doi.org/ 10.1016/B978-0-444-52910-7.00005-2

33. Robertson MM (2015) A personal 35 year perspective on Gilles de la Tourette syndrome: assessment, investigations, and management. Lancet Psychiatry 2:88-104. https://doi.org/10.1016/ S2215-0366(14)00133-3

34. Robertson MM, Eapen V, Singer HS et al (2017) Gilles de la Tourette syndrome. Nat Rev Dis Primers 3:16097. https://doi. org/10.1038/nrdp.2016.97

35. Robertson MM (2012) The Gilles de la Tourette syndrome: the current status. Arch Dis Child Educ Pract Ed 97:166-175. https:// doi.org/10.1136/archdischild-2011-300585

36. Shaw ZA, Coffey BJ (2014) Tics and Tourette syndrome. Psychiatr Clin North Am 37:269-286. https://doi.org/10.1016/j.psc. 2014.05.001

37. Singer HS (2019) Tics and Tourette syndrome. Continuum (Minneap Minn) 25:936-958. https://doi.org/10.1212/CON.00000 00000000752

38. Stern JS (2018) Tourette's syndrome and its borderland. Pract Neurol 18:262-270. https://doi.org/10.1136/pract neurol-2017-001755

39. Augustine F, Singer HS (2018) Merging the pathophysiology and pharmacotherapy of tics. Tremor Other Hyperkinet Mov (NY) 8:595. https://doi.org/10.7916/D8H14JTX

40. Billnitzer A, Jankovic J (2020) Current management of tics and tourette syndrome: behavioral, pharmacologic, and surgical treatments. Neurotherapeutics 17:1681-1693. https://doi.org/ 10.1007/s13311-020-00914-6

41. Chadehumbe MA, Brown LW (2019) Advances in the treatment of Tourette's disorder. Curr Psychiatry Rep 21:31. https://doi.org/ 10.1007/s11920-019-1018-z

42. Cothros N, Medina A, Pringsheim T (2020) Current pharmacotherapy for tic disorders. Expert Opin Pharmacother 21:567-580. https://doi.org/10.1080/14656566.2020.1721465

43. Egolf A, Coffey BJ (2014) Current pharmacotherapeutic approaches for the treatment of Tourette syndrome. Drugs Today (Barc) 50:159-179. https://doi.org/10.1358/dot.2014.50.2.20978 01

44. Essoe JK-Y, Grados MA, Singer HS et al (2019) Evidence-based treatment of Tourette's disorder and chronic tic disorders. Expert Rev Neurother 19:1103-1115. https://doi.org/10.1080/14737175. 2019.1643236

45. Hartmann A, Martino D, Murphy T (2016) Gilles de la Tourette syndrome-a treatable condition? Rev Neurol (Paris) 172:446454. https://doi.org/10.1016/j.neurol.2016.07.004

46. Hartmann A, Worbe Y (2013) Pharmacological treatment of Gilles de la Tourette syndrome. Neurosci Biobehav Rev 37:1157-1161. https://doi.org/10.1016/j.neubiorev.2012.10.014

47. Hartmann A, Worbe Y (2018) Tourette syndrome: clinical spectrum, mechanisms and personalized treatments. Curr Opin Neurol 31:504-509. https://doi.org/10.1097/WCO.0000000000 000575 
48. Jankovic J (2020) Treatment of tics associated with Tourette syndrome. J Neural Transm (Vienna). https://doi.org/10.1007/ s00702-019-02105-w

49. Jimenez-Shahed J (2020) Medical and surgical treatments of Tourette syndrome. Neurol Clin 38:349-366. https://doi.org/ 10.1016/j.ncl.2020.01.006

50. Malaty IA, Akbar U (2014) Updates in medical and surgical therapies for Tourette syndrome. Curr Neurol Neurosci Rep 14:458. https://doi.org/10.1007/s11910-014-0458-4

51. Mogwitz S, Buse J, Ehrlich S, Roessner V (2013) Clinical pharmacology of dopamine-modulating agents in Tourette's syndrome. Int Rev Neurobiol 112:281-349. https://doi.org/10. 1016/B978-0-12-411546-0.00010-X

52. Mogwitz S, Buse J, Wolff N, Roessner V (2018) Update on the pharmacological treatment of tics with dopamine-modulating agents. ACS Chem Neurosci 9:651-672. https://doi.org/10. 1021/acschemneuro.7b00460

53. Pandey S, Dash D (2019) Progress in pharmacological and surgical management of Tourette syndrome and other chronic tic disorders. Neurologist 24:93-108. https://doi.org/10.1097/ NRL.0000000000000218

54. Quezada J, Coffman KA (2018) Current approaches and new developments in the pharmacological management of Tourette syndrome. CNS Drugs 32:33-45. https://doi.org/10.1007/ s40263-017-0486-0

55. Rizzo R, Gulisano M (2020) Treatment options for tic disorders. Expert Rev Neurother 20:55-63. https://doi.org/10.1080/ 14737175.2020.1698950

56. Roessner V, Schoenefeld K, Buse J et al (2013) Pharmacological treatment of tic disorders and Tourette syndrome. Neuropharmacology 68:143-149. https://doi.org/10.1016/j.neuro pharm.2012.05.043

57. Roth J (2018) The colorful spectrum of Tourette syndrome and its medical, surgical and behavioral therapies. Parkinsonism Relat Disord 46(Suppl 1):S75-S79. https://doi.org/10.1016/j. parkreldis.2017.08.004

58. Seideman MF, Seideman TA (2020) A review of the current treatment of Tourette syndrome. J Pediatr Pharmacol Ther 25:401-412. https://doi.org/10.5863/1551-6776-25.5.401

59. Serajee FJ, Mahbubul Huq AHM (2015) Advances in Tourette syndrome: diagnoses and treatment. Pediatr Clin North Am 62:687-701. https://doi.org/10.1016/j.pcl.2015.03.007

60. Shprecher DR, Schrock L, Himle M (2014) Neurobehavioral aspects, pathophysiology, and management of Tourette syndrome. Curr Opin Neurol 27:484-492. https://doi.org/10.1097/ WCO.0000000000000119

61. Shprecher DR, Kious BM, Himle MH (2015) Advances in mechanistic understanding and treatment approaches to Tourette syndrome. Discov Med 20:295-301

62. Tagwerker Gloor F, Walitza S (2016) Tic disorders and Tourette syndrome: current concepts of etiology and treatment in children and adolescents. Neuropediatrics 47:84-96. https:// doi.org/10.1055/s-0035-1570492

63. Thenganatt MA, Jankovic $\mathbf{J}$ (2016) Recent advances in understanding and managing Tourette syndrome. F1000Res 5. https://doi.org/10.12688/f1000research.7424.1

64. Thomas R, Cavanna AE (2013) The pharmacology of Tourette syndrome. J Neural Transm 120:689-694. https://doi.org/10. 1007/s00702-013-0979-z

65. Cox JH, Seri S, Cavanna AE (2016) Safety and efficacy of aripiprazole for the treatment of pediatric Tourette syndrome and other chronic tic disorders. Pediatr Health Med Ther 7:57-64. https://doi.org/10.2147/PHMT.S87121

66. Ghanizadeh A (2012) Systemic review of aripiprazole for the treatment of children and adolescents with tic disorders. Neurosciences (Riyadh) 17:200-204
67. Janik P, Szejko N (2018) Aripiprazole in treatment of Gilles de la Tourette syndrome-new therapeutic option. Neurol Neurochir Pol 52:84-87. https://doi.org/10.1016/j.pjnns.2017.10.015

68. Liu Y, Ni H, Wang C et al (2016) Effectiveness and tolerability of aripiprazole in children and adolescents with Tourette's disorder: a meta-analysis. J Child Adolesc Psychopharmacol 26:436-441. https://doi.org/10.1089/cap.2015.0125

69. Wang S, Wei Y-Z, Yang J-H et al (2017) The efficacy and safety of aripiprazole for tic disorders in children and adolescents: a systematic review and meta-analysis. Psychiatry Res 254:24-32. https://doi.org/10.1016/j.psychres.2017.04.013

70. Yang C, Yi Q, Zhang L et al (2019) Safety of aripiprazole for tics in children and adolescents: a systematic review and metaanalysis. Medicine (Baltimore) 98:e15816. https://doi.org/10. 1097/MD.0000000000015816

71. Yang C-S, Huang H, Zhang L-L et al (2015) Aripiprazole for the treatment of tic disorders in children: a systematic review and meta-analysis. BMC Psychiatry 15:179. https://doi.org/10.1186/ s12888-015-0504-Z

72. Zheng W, Li X-B, Xiang Y-Q et al (2016) Aripiprazole for Tourette's syndrome: a systematic review and meta-analysis. Hum Psychopharmacol 31:11-18. https://doi.org/10.1002/hup.2498

73. Budman CL (2014) The role of atypical antipsychotics for treatment of Tourette's syndrome: an overview. Drugs 74:1177-1193. https://doi.org/10.1007/s40265-014-0254-0

74. Anandan C, Jankovic J (2021) Botulinum toxin in movement disorders: an update. Toxins (Basel). https://doi.org/10.3390/ toxins 13010042

75. Anandan S, Wigg CL, Thomas CR, Coffey B (2004) Psychosurgery for self-injurious behavior in Tourette's disorder. J Child Adolesc Psychopharmacol 14:531-538. https://doi.org/10.1089/ cap.2004.14.531

76. Awan KH (2017) The therapeutic usage of botulinum toxin (Botox) in non-cosmetic head and neck conditions-an evidence based review. Saudi Pharm J 25:18-24. https://doi.org/10.1016/j. jsps.2016.04.024

77. Camargo CHF, Teive HAG (2019) Use of botulinum toxin for movement disorders. Drugs Context. https://doi.org/10.7573/dic. 212586

78. Hallett M, Albanese A, Dressler D et al (2013) Evidence-based review and assessment of botulinum neurotoxin for the treatment of movement disorders. Toxicon 67:94-114. https://doi.org/10. 1016/j.toxicon.2012.12.004

79. Jankovic J (2018) An update on new and unique uses of botulinum toxin in movement disorders. Toxicon 147:84-88. https:// doi.org/10.1016/j.toxicon.2017.09.003

80. Lotia M, Jankovic J (2016) Botulinum toxin for the treatment of tremor and tics. Semin Neurol 36:54-63. https://doi.org/10. $1055 / \mathrm{s}-0035-1571217$

81. Moretti A (2020) Is botulinum toxin effective and safe for motor and phonic tics in patients affected by Tourette syndrome? A Cochrane Review summary with commentary. Dev Med Child Neurol 62:274-276. https://doi.org/10.1111/dmcn.14472

82. Persaud R, Garas G, Silva S et al (2013) An evidence-based review of botulinum toxin (Botox) applications in non-cosmetic head and neck conditions. JRSM Short Rep 4:10. https://doi.org/ $10.1177 / 2042533312472115$

83. Safarpour Y, Jabbari B (2018) Botulinum toxin treatment of movement disorders. Curr Treat Options Neurol 20:4. https:// doi.org/10.1007/s11940-018-0488-3

84. Tater P, Pandey S (2018) Botulinum toxin in movement disorders. Neurol India 66:S79-S89. https://doi.org/10.4103/00283886.226441

85. Thenganatt MA, Fahn S (2012) Botulinum toxin for the treatment of movement disorders. Curr Neurol Neurosci Rep 12:399-409. https://doi.org/10.1007/s11910-012-0286-3 
86. Artukoglu BB, Bloch MH (2019) The potential of cannabinoidbased treatments in Tourette syndrome. CNS Drugs 33:417-430. https://doi.org/10.1007/s40263-019-00627-1

87. Koppel BS (2015) Cannabis in the treatment of dystonia, dyskinesias, and tics. Neurotherapeutics 12:788-792. https://doi.org/ 10.1007/s13311-015-0376-4

88. Müller-Vahl KR (2013) Treatment of Tourette syndrome with cannabinoids. Behav Neurol 27:119-124. https://doi.org/10. 3233/BEN-120276

89. Wang S, Wei Y-Z, Yang J et al (2017) Clonidine adhesive patch for the treatment of tic disorders: a systematic review and metaanalysis. Eur J Paediatr Neurol 21:614-620. https://doi.org/10. 1016/j.ejpn.2017.03.003

90. Weisman H, Qureshi IA, Leckman JF et al (2013) Systematic review: pharmacological treatment of tic disorders-efficacy of antipsychotic and alpha-2 adrenergic agonist agents. Neurosci Biobehav Rev 37:1162-1171. https://doi.org/10.1016/j.neubi orev.2012.09.008

91. Kumar A, Duda L, Mainali G et al (2018) A comprehensive review of Tourette syndrome and complementary alternative medicine. Curr Dev Disord Rep 5:95-100. https://doi.org/10. 1007/s40474-018-0137-2

92. Paton DM (2017) Deutetrabenazine: treatment of hyperkinetic aspects of Huntington's disease, tardive dyskinesia and Tourette syndrome. Drugs Today (Barc) 53:89-102. https://doi.org/10. 1358/dot.2017.53.2.2589164

93. Hartmann A (2013) Clinical pharmacology of nondopaminergic drugs in Tourette syndrome. Int Rev Neurobiol 112:351-372. https://doi.org/10.1016/B978-0-12-411546-0.00011-1

94. Qi H, Liu R, Zheng W et al (2020) Efficacy and safety of traditional Chinese medicine for Tourette's syndrome: a meta-analysis of randomized controlled trials. Asian J Psychiatr 47:101853. https://doi.org/10.1016/j.ajp.2019.101853

95. Yang C-S, Zhang L-L, Zeng L-N et al (2013) Topiramate for Tourette's syndrome in children: a meta-analysis. Pediatr Neurol 49:344-350. https://doi.org/10.1016/j.pediatrneurol.2013.05.002

96. Yu L, Yan J, Wen F et al (2020) Revisiting the efficacy and tolerability of topiramate for tic disorders: a meta-analysis. J Child Adolesc Psychopharmacol. https://doi.org/10.1089/cap.2019. 0161

97. El Malhany N, Gulisano M, Rizzo R, Curatolo P (2015) Tourette syndrome and comorbid ADHD: causes and consequences. Eur J Pediatr 174:279-288. https://doi.org/10.1007/ s00431-014-2417-0

98. Ogundele MO, Ayyash HF (2018) Review of the evidence for the management of co-morbid tic disorders in children and adolescents with attention deficit hyperactivity disorder. World J Clin Pediatr 7:36-42. https://doi.org/10.5409/wjcp.v7.i1.36

99. Osland ST, Steeves TD, Pringsheim T (2018) Pharmacological treatment for attention deficit hyperactivity disorder (ADHD) in children with comorbid tic disorders. Cochrane Database Syst Rev 6:CD007990. https://doi.org/10.1002/14651858.CD007990. pub3

100. Pringsheim T, Steeves T (2011) Pharmacological treatment for attention deficit hyperactivity disorder (ADHD) in children with comorbid tic disorders. Cochrane Database Syst Rev CD007990. https://doi.org/10.1002/14651858.CD007990.pub2

101. Rizzo R, Gulisano M, Calì PV, Curatolo P (2013) Tourette Syndrome and comorbid ADHD: current pharmacological treatment options. Eur J Paediatr Neurol 17:421-428. https://doi.org/10. 1016/j.ejpn.2013.01.005

102. Rizzo R, Gulisano M (2013) Clinical pharmacology of comorbid attention deficit hyperactivity disorder in Tourette syndrome. Int Rev Neurobiol 112:415-444. https://doi.org/10.1016/B978-0-12411546-0.00014-7
103. Yang R, Li R, Gao W, Zhao Z (2017) Tic symptoms induced by atomoxetine in treatment of ADHD: a case report and literature review. J Dev Behav Pediatr 38:151-154. https://doi.org/10.1097/ DBP.0000000000000371

104. Neri V, Cardona F (2013) Clinical pharmacology of comorbid obsessive-compulsive disorder in Tourette syndrome. Int Rev Neurobiol 112:391-414. https://doi.org/10.1016/B978-0-12411546-0.00013-5

105. Rothenberger A, Roessner V (2019) Psychopharmacotherapy of obsessive-compulsive symptoms within the framework of Tourette syndrome. Curr Neuropharmacol 17:703-709. https://doi. org/10.2174/1570159X16666180828095131

106. Martino D, Hedderly T (2019) Tics and stereotypies: a comparative clinical review. Parkinsonism Relat Disord 59:117-124. https://doi.org/10.1016/j.parkreldis.2019.02.005

107. Rajapakse T, Pringsheim T (2010) Pharmacotherapeutics of Tourette syndrome and stereotypies in autism. Semin Pediatr Neurol 17:254-260. https://doi.org/10.1016/j.spen.2010.10.008

108. Madruga-Garrido M, Mir P (2013) Tics and other stereotyped movements as side effects of pharmacological treatment. Int Rev Neurobiol 112:481-494. https://doi.org/10.1016/B978-012-411546-0.00016-0

109. Rath JJG, Deen MEJ, van Houten H et al (2017) Antipsychoticinduced hyperprolactinemia in Tourette syndrome. Ther Adv Psychopharmacol 7:201-205. https://doi.org/10.1177/20451 25317705012

110. Kious BM, Jimenez-Shahed J, Shprecher DR (2016) Treatmentrefractory Tourette Syndrome. Prog Neuropsychopharmacol Biol Psychiatry 70:227-236. https://doi.org/10.1016/j.pnpbp.2016.02. 003

111. Roessner V, Plessen KJ, Rothenberger A et al (2011) European clinical guidelines for Tourette syndrome and other tic disorders. Part II: pharmacological treatment. Eur Child Adolesc Psychiatry 20:173-196. https://doi.org/10.1007/s00787-011-0163-7

112. Buse J, Schoenefeld K, Münchau A, Roessner V (2013) Neuromodulation in Tourette syndrome: dopamine and beyond. Neurosci Biobehav Rev 37:1069-1084. https://doi.org/10.1016/j.neubi orev.2012.10.004

113. Putignano D, Clavenna A, Reale L, Bonati M (2019) The evidence-based choice for antipsychotics in children and adolescents should be guaranteed. Eur J Clin Pharmacol 75:769-776. https:// doi.org/10.1007/s00228-019-02641-0

114. Bruun RD (1988) Subtle and underrecognized side effects of neuroleptic treatment in children with Tourette's disorder. Am J Psychiatry 145:621-624

115. Singer HS (2010) Treatment of tics and tourette syndrome. Curr Treat Options Neurol 12:539-561. https://doi.org/10.1007/ s11940-010-0095-4

116. Roessner V, Wolff N, Ehrlich S, Waltereit R (2017) Need for a more developmental perspective: QTc prolongation under psychotropic medication. Eur Child Adolesc Psychiatry 26:871-873. https://doi.org/10.1007/s00787-017-1028-5

117. Haddad PM, Wieck A (2004) Antipsychotic-induced hyperprolactinaemia: mechanisms, clinical features and management. Drugs 64:2291-2314

118. Ho J, Panagiotopoulos C, McCrindle B et al (2011) Management recommendations for metabolic complications associated with second-generation antipsychotic use in children and youth. Paediatr Child Health 16:575-580

119. Pringsheim T, Pearce M (2010) Complications of antipsychotic therapy in children with Tourette syndrome. Pediatr Neurol 43:17-20. https://doi.org/10.1016/j.pediatrneurol.2010.02.012

120. Solmi M, Fornaro M, Ostinelli EG et al (2020) Safety of 80 antidepressants, antipsychotics, anti-attention-deficit/hyperactivity medications and mood stabilizers in children and adolescents with psychiatric disorders: a large scale systematic meta-review 
of 78 adverse effects. World Psychiatry 19:214-232. https://doi. org/10.1002/wps. 20765

121. Eddy CM, Rickards HE, Cavanna AE (2011) Treatment strategies for tics in Tourette syndrome. Ther Adv Neurol Disord 4:25-45. https://doi.org/10.1177/1756285610390261

122. Pringsheim T, Marras C (2009) Pimozide for tics in Tourette's syndrome. Cochrane Database Syst Rev CD006996. https://doi. org/10.1002/14651858.CD006996.pub2

123. Rizzo R, Eddy CM, Calí P et al (2012) Metabolic effects of aripiprazole and pimozide in children with Tourette syndrome. Pediatr Neurol 47:419-422. https://doi.org/10.1016/j.pediatrneu rol.2012.08.015

124. Yang C, Hao Z, Zhu C et al (2016) Interventions for tic disorders: an overview of systematic reviews and meta analyses. Neurosci Biobehav Rev 63:239-255. https://doi.org/10.1016/j.neubiorev. 2015.12.013

125. Gulisano M, Calì PV, Cavanna $\mathrm{AE}$ et al (2011) Cardiovascular safety of aripiprazole and pimozide in young patients with Tourette syndrome. Neurol Sci 32:1213-1217. https://doi.org/ 10.1007/s 10072-011-0678-1

126. Janssen PA, Niemegeers CJ, Awouters F et al (1988) Pharmacology of risperidone (R 64766 ), a new antipsychotic with serotonin-S2 and dopamine-D2 antagonistic properties. J Pharmacol Exp Ther 244:685-693

127. Ghanizadeh A, Haghighi A (2014) Aripiprazole versus risperidone for treating children and adolescents with tic disorder: a randomized double blind clinical trial. Child Psychiatry Hum Dev 45:596-603. https://doi.org/10.1007/s10578-013-0427-1

128. Pringsheim T, Ho J, Sarna JR et al (2017) Feasibility and relevance of antipsychotic safety monitoring in children with Tourette syndrome: a prospective longitudinal study. J Clin Psychopharmacol 37:498-504. https://doi.org/10.1097/JCP.0000000000 000760

129. Calarge CA, Xie D, Fiedorowicz JG et al (2012) Rate of weight gain and cardiometabolic abnormalities in children and adolescents. J Pediatr 161:1010-1015. https://doi.org/10.1016/j.jpeds. 2012.05.051

130. Barton BB, Segger F, Fischer K et al (2020) Update on weightgain caused by antipsychotics: a systematic review and metaanalysis. Expert Opin Drug Saf 19:295-314. https://doi.org/10. 1080/14740338.2020.1713091

131. Burris KD, Molski TF, Xu C et al (2002) Aripiprazole, a novel antipsychotic, is a high-affinity partial agonist at human dopamine D2 receptors. J Pharmacol Exp Ther 302:381-389

132. Lawler CP, Prioleau C, Lewis MM et al (1999) Interactions of the novel antipsychotic aripiprazole (OPC-14597) with dopamine and serotonin receptor subtypes. Neuropsychopharmacology 20:612-627. https://doi.org/10.1016/S0893-133X(98)00099-2

133. Kikuchi T, Tottori K, Uwahodo $\mathrm{Y}$ et al (1995) 7-(4-[4-(2,3-Dichlorophenyl)-1-piperazinyl]butyloxy)-3,4-dihydro-2(1H)-quinolinone (OPC-14597), a new putative antipsychotic drug with both presynaptic dopamine autoreceptor agonistic activity and postsynaptic D2 receptor antagonistic activity. J Pharmacol Exp Ther 274:329-336

134. Jordan S, Koprivica V, Chen R et al (2002) The antipsychotic aripiprazole is a potent, partial agonist at the human 5-HT1A receptor. Eur J Pharmacol 441:137-140

135. Wenzel C, Kleimann A, Bokemeyer S, Müller-Vahl KR (2012) Aripiprazole for the treatment of Tourette syndrome: a case series of 100 patients. J Clin Psychopharmacol 32:548-550. https://doi.org/10.1097/JCP.0b013e31825ac2cb

136. Sallee F, Kohegyi E, Zhao J et al (2017) Randomized, doubleblind, placebo-controlled trial demonstrates the efficacy and safety of oral aripiprazole for the treatment of Tourette's disorder in children and adolescents. J Child Adolesc Psychopharmacol. https://doi.org/10.1089/cap.2016.0026
137. Yoo HK, Joung YS, Lee J-S et al (2013) A multicenter, randomized, double-blind, placebo-controlled study of aripiprazole in children and adolescents with Tourette's disorder. J Clin Psychiatry 74:e772-780. https://doi.org/10.4088/JCP.12m08189

138. Zheng Y, Zhang Z-J, Han X-M et al (2016) A proprietary herbal medicine (5-Ling Granule) for Tourette syndrome: a randomized controlled trial. J Child Psychol Psychiatry 57:74-83. https://doi. org/10.1111/jcpp.12432

139. Wang L-J, Chou W-J, Chou M-C, Gau SS-F (2016) The Effectiveness of aripiprazole for tics, social adjustment, and parental stress in children and adolescents with Tourette's disorder. J Child Adolesc Psychopharmacol 26:442-448. https://doi.org/ 10.1089/cap.2015.0104

140. Salvador A, Worbe Y, Delorme C et al (2017) Specific effect of a dopamine partial agonist on counterfactual learning: evidence from Gilles de la Tourette syndrome. Sci Rep 7:6292. https://doi. org/10.1038/s41598-017-06547-8

141. Leucht S, Cipriani A, Spineli L et al (2013) Comparative efficacy and tolerability of 15 antipsychotic drugs in schizophrenia: a multiple-treatments meta-analysis. Lancet 382:951-962. https:// doi.org/10.1016/S0140-6736(13)60733-3

142. Bernagie C, Danckaerts M, Wampers M, De Hert M (2016) Aripiprazole and acute extrapyramidal symptoms in children and adolescents: a meta-analysis. CNS Drugs 30:807-818. https:// doi.org/10.1007/s40263-016-0367-y

143. Pillinger T, McCutcheon RA, Vano L et al (2020) Comparative effects of 18 antipsychotics on metabolic function in patients with schizophrenia, predictors of metabolic dysregulation, and association with psychopathology: a systematic review and network meta-analysis. Lancet Psychiatry 7:64-77. https://doi.org/ 10.1016/S2215-0366(19)30416-X

144. Bachmann CJ, Roessner V, Glaeske G, Hoffmann F (2015) Trends in psychopharmacologic treatment of tic disorders in children and adolescents in Germany. Eur Child Adolesc Psychiatry 24:199-207. https://doi.org/10.1007/s00787-014-0563-6

145. Dose M, Lange HW (2000) The benzamide tiapride: treatment of extrapyramidal motor and other clinical syndromes. Pharmacopsychiatry 33:19-27. https://doi.org/10.1055/s-2000-7964

146. Eggers C, Rothenberger A, Berghaus U (1988) Clinical and neurobiological findings in children suffering from tic disease following treatment with tiapride. Eur Arch Psychiatry Neurol Sci 237:223-229

147. Fekete S, Egberts K, Preissler T et al (2021) Estimation of a preliminary therapeutic reference range for children and adolescents with tic disorders treated with tiapride. Eur J Clin Pharmacol 77:163-170. https://doi.org/10.1007/s00228-020-03000-0

148. Soares KV, McGrath JJ (1999) The treatment of tardive dyskinesia-a systematic review and meta-analysis. Schizophr Res 39:1-16; discussion 17-18. https://doi.org/10.1016/s09209964(99)00021-3

149. Song P-P, Jiang L, Li X-J et al (2017) The efficacy and tolerability of the clonidine transdermal patch in the treatment for children with tic disorders: a prospective, open, single-group. Self-controlled study. Front Neurol 8:32. https://doi.org/10.3389/ fneur.2017.00032

150. Hirota T, Schwartz S, Correll CU (2014) Alpha-2 agonists for attention-deficit/hyperactivity disorder in youth: a systematic review and meta-analysis of monotherapy and add-on trials to stimulant therapy. J Am Acad Child Adolesc Psychiatry 53:153173. https://doi.org/10.1016/j.jaac.2013.11.009

151. Reid JL, Campbell BC, Hamilton CA (1984) Withdrawal reactions following cessation of central alpha-adrenergic receptor agonists. Hypertension 6:II71-II75. https://doi.org/10.1161/01. hyp.6.5_pt_2.ii71

152. Daviss WB, Patel NC, Robb AS et al (2008) Clonidine for attention-deficit/hyperactivity disorder: II. ECG changes and 
adverse events analysis. J Am Acad Child Adolesc Psychiatry 47:189-198

153. Murphy TK, Fernandez TV, Coffey BJ et al (2017) Extendedrelease guanfacine does not show a large effect on tic severity in children with chronic tic disorders. J Child Adolesc Psychopharmacol 27:762-770. https://doi.org/10.1089/cap.2017.0024

154. Sallee F, McGough J, Wigal T et al (2008) Guanfacine extended release in children and adolescents with attention-deficit/hyperactivity disorder: a placebo-controlled trial. J Am Acad Child Adolesc Psychiatry 48(2):155-165

155. Elbe D, Perel-Panar C, Wicholas L (2016) Manic reaction in a child induced by guanfacine-extended release. J Child Adolesc Psychopharmacol 26:566-567. https://doi.org/10.1089/cap.2016. 0050

156. Horrigan JP, Barnhill LJ (1999) Guanfacine and secondary mania in children. J Affect Disord 54:309-314

157. Sandyk R, Awerbuch G (1988) Marijuana and Tourette's syndrome. J Clin Psychopharmacol 8:444-445. https://doi.org/10. 1097/00004714-198812000-00021

158. Milosev LM, Psathakis N, Szejko N et al (2019) Treatment of Gilles de la Tourette syndrome with cannabis-based medicine: results from a retrospective analysis and online survey. Cannabis Cannabinoid Res 4:265-274. https://doi.org/10.1089/can.2018. 0050

159. Black N, Stockings E, Campbell G et al (2019) Cannabinoids for the treatment of mental disorders and symptoms of mental disorders: a systematic review and meta-analysis. Lancet Psychiatry 6:995-1010. https://doi.org/10.1016/S2215-0366(19)30401-8

160. Müller-Vahl KR, Schneider U, Prevedel H et al (2003) Delta 9-tetrahydrocannabinol (THC) is effective in the treatment of tics in Tourette syndrome: a 6-week randomized trial. J Clin Psychiatry 64:459-465. https://doi.org/10.4088/jcp.v64n0417

161. Müller-Vahl KR, Schneider U, Koblenz A et al (2002) Treatment of Tourette's syndrome with delta 9-tetrahydrocannabinol (THC): a randomized crossover trial. Pharmacopsychiatry 35:57-61. https://doi.org/10.1055/s-2002-25028

162. Marras C, Andrews D, Sime E, Lang AE (2001) Botulinum toxin for simple motor tics: a randomized, double-blind, controlled clinical trial. Neurology 56:605-610

163. Abuzzahab FS, Brown VL (2001) Control of Tourette's syndrome with topiramate. Am J Psychiatry 158:968

164. Jankovic J, Jimenez-Shahed J, Brown LW (2010) A randomised, double-blind, placebo-controlled study of topiramate in the treatment of Tourette syndrome. J Neurol Neurosurg Psychiatr 81:70-73. https://doi.org/10.1136/jnnp.2009.185348

165. Choi J, Yoon D, Park M et al (2020) Topiramate-related adverse events: pattern and signals in the Korea Adverse Event Reporting System, 2010-2017. Medicine (Baltimore) 99:e22669. https:// doi.org/10.1097/MD.0000000000022669

166. Müller O, Rothenberger A, Brüni GL et al (2018) Questioning the long-term stability of the additive model in comorbid CTD+ADHD - the transition from childhood to adulthood. PLoS ONE 13:e0207522. https://doi.org/10.1371/journal.pone. 0207522

167. Roessner V, Becker A, Banaschewski T, Rothenberger A (2007) Psychopathological profile in children with chronic tic disorder and co-existing ADHD: additive effects. J Abnorm Child Psychol 35:79-85. https://doi.org/10.1007/s10802-006-9086-z

168. Cardona F, Rizzo R (2013) Treatment of psychiatric comorbidities in Tourette syndromes. Oxford University Press, Oxford

169. Groth C, Mol Debes N, Rask CU et al (2017) Course of Tourette syndrome and comorbidities in a large prospective clinical study. J Am Acad Child Adolesc Psychiatry 56:304-312. https://doi. org/10.1016/j.jaac.2017.01.010

170. Groth C (2018) Tourette syndrome in a longitudinal perspective. Clinical course of tics and comorbidities, coexisting psychopathologies, phenotypes and predictors. Dan Med J 65:155-165

171. Castellanos FX (1999) Stimulants and tic disorders: from dogma to data. Arch Gen Psychiatry 56:337-338

172. Roessner V, Robatzek M, Knapp G et al (2006) First-onset tics in patients with attention-deficit-hyperactivity disorder: impact of stimulants. Dev Med Child Neurol 48:616-621. https://doi.org/ 10.1017/S0012162206001290

173. Tourette's Syndrome Study Group (2002) Treatment of ADHD in children with tics: a randomized controlled trial. Neurology 58:527-536

174. Palumbo D, Spencer T, Lynch J et al (2004) Emergence of tics in children with ADHD: impact of once-daily OROS methylphenidate therapy. J Child Adolesc Psychopharmacol 14:185-194

175. Masi G, Gagliano A, Siracusano R et al (2012) Aripiprazole in children with Tourette's disorder and co-morbid attention-deficit/ hyperactivity disorder: a 12-week, open-label, preliminary study. J Child Adolesc Psychopharmacol 22:120-125. https://doi.org/ 10.1089/cap.2011.0081

176. Hirschtritt ME, Lee PC, Pauls DL et al (2015) Lifetime prevalence, age of risk, and genetic relationships of comorbid psychiatric disorders in Tourette syndrome. JAMA Psychiat 72:325333. https://doi.org/10.1001/jamapsychiatry.2014.2650

177. Conelea CA, Walther MR, Freeman JB et al (2014) Tic-related obsessive-compulsive disorder (OCD): phenomenology and treatment outcome in the pediatric OCD treatment study II. J Am Acad Child Adolesc Psychiatry 53:1308-1316. https://doi. org/10.1016/j.jaac.2014.09.014

178. March JS, Franklin ME, Leonard H et al (2007) Tics moderate treatment outcome with sertraline but not cognitive-behavior therapy in pediatric obsessive-compulsive disorder. Biol Psychiatry 61:344-347. https://doi.org/10.1016/j.biopsych.2006.09. 035

179. Bloch MH, Landeros-Weisenberger A, Kelmendi B et al (2006) A systematic review: antipsychotic augmentation with treatment refractory obsessive-compulsive disorder. Mol Psychiatry 11:622-632. https://doi.org/10.1038/sj.mp.4001823

180. Masi G, Pfanner C, Brovedani P (2013) Antipsychotic augmentation of selective serotonin reuptake inhibitors in resistant tic-related obsessive-compulsive disorder in children and adolescents: a naturalistic comparative study. J Psychiatr Res 47:1007-1012. https://doi.org/10.1016/j.jpsychires.2013.04.003

181. Veale D, Miles S, Smallcombe N et al (2014) Atypical antipsychotic augmentation in SSRI treatment refractory obsessive-compulsive disorder: a systematic review and meta-analysis. BMC Psychiatry 14:317. https://doi.org/10.1186/s12888-014-0317-5

182. Fernández de la Cruz L, Rydell M, Runeson B et al (2017) Suicide in Tourette's and chronic tic disorders. Biol Psychiatry 82:111-118. https://doi.org/10.1016/j.biopsych.2016.08.023

183. Bartram LA, Lozano J, Coury DL (2019) Aripiprazole for treating irritability associated with autism spectrum disorders. Expert Opin Pharmacother 20:1421-1427. https://doi.org/10.1080/ 14656566.2019.1626825

184. Findling RL, Youngstrom EA, Rowles BM et al (2017) A doubleblind and placebo-controlled trial of aripiprazole in symptomatic youths at genetic high risk for bipolar disorder. J Child Adolesc Psychopharmacol 27:864-874. https://doi.org/10.1089/cap.2016. 0160

185. Hirsch LE, Pringsheim T (2016) Aripiprazole for autism spectrum disorders (ASD). Cochrane Database Syst Rev CD009043. https://doi.org/10.1002/14651858.CD009043.pub3

186. Sandor P, Stephens RJ (2000) Risperidone treatment of aggressive behavior in children with Tourette syndrome. J Clin Psychopharmacol 20:710-712

187. Wolff N, Hebebrand J, Roessner V (2020) 19 Tics und motorische stereotypien. In: Remschmidt H (ed) Kinder- und 
jugendpsychiatrie und psychotherapie, 7th edn. Thieme Verlag, Heidelberg, pp 186-193

188. Verdellen C, van de Griendt J, Hartmann A et al (2011) European clinical guidelines for Tourette syndrome and other tic disorders. Part III: behavioural and psychosocial interventions. Eur Child Adolesc Psychiatry 20:197-207. https://doi.org/10.1007/ s00787-011-0167-3

189. Hamamura T, Harada $T$ (2007) Unique pharmacological profile of aripiprazole as the phasic component buster. Psychopharmacology 191:741-743. https://doi.org/10.1007/s00213-006-0654-2

190. Kapur S, Zipursky R, Jones C et al (2000) Relationship between dopamine $\mathrm{D}(2)$ occupancy, clinical response, and side effects: a double-blind PET study of first-episode schizophrenia. Am J Psychiatry 157:514-520. https://doi.org/10.1176/appi.ajp.157.4. 514

191. Yokoi F, Gründer G, Biziere K et al (2002) Dopamine D2 and D3 receptor occupancy in normal humans treated with the antipsychotic drug aripiprazole (OPC 14597): a study using positron emission tomography and [11C]raclopride. Neuropsychopharmacology 27:248-259. https://doi.org/10.1016/S0893-133X(02) 00304-4
192. Rizzo R, Pellico A, Silvestri PR et al (2018) A randomized controlled trial comparing behavioral, educational, and pharmacological treatments in youths with chronic tic disorder or Tourette syndrome. Front Psychiatry 9:100. https://doi.org/10.3389/fpsyt. 2018.00100

193. Macerollo A, Martino D, Cavanna AE et al (2016) Refractoriness to pharmacological treatment for tics: a multicentre European audit. J Neurol Sci 366:136-138. https://doi.org/10.1016/j.jns. 2016.05.004

194. Posner J (2018) The role of precision medicine in child psychiatry: what can we expect and when? J Am Acad Child Adolesc Psychiatry 57:813-817. https://doi.org/10.1016/j.jaac.2018.07. 874

195. Roessner V, Rothe J, Kohls G, Schomerus G, Ehrlich S, Beste C (2021) Taming the chaos?! Using eXplainable Artificial Intelligence (XAI) to tackle the complexity in mental health research Eur Child Adolesc Psychiatry 30(8):1143-1146. https://doi.org/ 10.1007/s00787-021-01836-0

\section{Authors and Affiliations}

\section{Veit Roessner ${ }^{1} \cdot$ Heike Eichele ${ }^{2,3} \cdot$ Jeremy S. Stern $^{4} \cdot$ Liselotte Skov $^{5} \cdot$ Renata Rizzo $^{6} \cdot$ Nanette Mol Debes $^{5}$. Péter Nagy ${ }^{7}$ Andrea E. Cavanna ${ }^{8}$. Cristiano Termine ${ }^{9} \cdot$ Christos Ganos $^{10} \cdot$ Alexander Münchau $^{11}$. Natalia Szejko ${ }^{12,13,14}$. Danielle Cath ${ }^{15}$. Kirsten R. Müller-Vahl ${ }^{16} \cdot$ Cara Verdellen $^{17,18} \cdot$ Andreas Hartmann $^{19,20}$. Aribert Rothenberger $^{21} \cdot$ Pieter J. Hoekstra $^{22} \cdot$ Kerstin J. Plessen $^{23,24}$}

1 Department of Child and Adolescent Psychiatry, TU Dresden, Fetscherstrasse 74, 01307 Dresden, Germany

2 Department of Biological and Medical Psychology, Faculty of Psychology, University of Bergen, Bergen, Norway

3 Regional Resource Center for Autism, ADHD, Tourette Syndrome and Narcolepsy Western Norway, Division of Psychiatry, Haukeland University Hospital, Bergen, Norway

4 Department of Neurology, St George's Hospital, St George's University of London, London, UK

5 Paediatric Department, Herlev University Hospital, Herlev, Denmark

6 Child and Adolescent Neurology and Psychiatry, Department of Clinical and Experimental Medicine, University of Catania, Catania, Italy

7 Vadaskert Child Psychiatric Hospital and Outpatient Clinic, Budapest, Hungary

8 Institute of Clinical Sciences, University of Birmingham, Birmingham, UK

9 Child Neuropsychiatry Unit, Department of Medicine and Surgery, University of Insubria, Varese, Italy

10 Department of Neurology, Charité Universitätsmedizin Berlin, Berlin, Germany

11 Institute of Systems Motor Science, University of Lübeck, Lübeck, Germany

12 Department of Neurology, Medical University of Warsaw, Warsaw, Poland
13 Department of Bioethics, Medical University of Warsaw, Warsaw, Poland

14 Division of Neurocritical Care and Emergency Neurology, Department of Neurology, Yale School of Medicine, New Haven, CT, USA

15 Department of Psychiatry, University Medical Center Groningen, Rijks Universiteit Groningen, GGZ Drenthe Mental Health Institution, Assen, The Netherlands

16 Clinic of Psychiatry, Social Psychiatry and Psychotherapy, Hannover Medical School, Hannover, Germany

17 PsyQ Nijmegen, Parnassia Group, Nijmegen, The Netherlands

18 TicXperts, Heteren, The Netherlands

19 Department of Neurology, Sorbonne Université, Pitié-Salpetriere Hospital, Paris, France

20 National Reference Center for Tourette Disorder, Pitié Salpetiere Hospital, Paris, France

21 Clinic for Child and Adolescent Psychiatry and Psychotherapy, University Medical Center Gottingen, Gottingen, Germany

22 Department of Child and Adolescent Psychiatry, University of Groningen, University Medical Center Groningen, Groningen, Netherlands

23 Division of Child and Adolescent Psychiatry, Department of Psychiatry, Lausanne University Hospital, University of Lausanne, Lausanne, Switzerland

24 Child and Adolescent Mental Health Centre, Mental Health Services, Capital Region of Denmark, Copenhagen, Denmark 